\title{
Impacto do Glyphosate Associado a InSETICIDA E FUngicida NA Atividade Microbiana e no Potencial de Solubilização de Fosfato Em Solo Cultivado com SoJa RounduP REAdY ${ }^{\circledR 1}$
}

\author{
Impact of Glyphosate Associated with Insecticide and Fungicide Application on the Microbial \\ Activity and Potential Phosphate Solubilization in Soil Cultivated with Roundup Ready ${ }^{\circledR}$ Soybean
}

\author{
REIS, M.R. ${ }^{2}$, SILVA, A.A. ${ }^{3}$, FREITAS, M.A.M. ${ }^{4}$, PEREIRA, J.L. ${ }^{2}$, COSTA, M.D. ${ }^{5}$, PICANÇO, M.C. ${ }^{6}$, \\ FERREIRA, E.A. ${ }^{7}$, BELO, A.F. ${ }^{2}$, COELHO, A.T.C.P. ${ }^{4}$ e SILVA, G.R. ${ }^{4}$
}

\begin{abstract}
RESUMO - Objetivou-se com este trabalho avaliar a atividade microbiana e o potencial de solubilização de fosfato inorgânico em solos cultivados com soja sob diferentes manejos fitossanitários. O experimento foi conduzido em campo, em Argissolo Vermelho-Amarelo câmbico. Foram avaliados dez tratamentos em delineamento de blocos casualizados, no esquema de parcelas subdivididas, com quatro repetições. Nas parcelas, avaliou-se o efeito da aplicação ou não da mistura de inseticida (endossulfan) + fungicida (tebuconazole) e, nas subparcelas, o efeito dos métodos de controle de plantas daninhas (testemunha não capinada, testemunha capinada, aplicação única de glyphosate, aplicação sequencial de glyphosate e aplicação única de fomesafen + fluazifop-p-butil). Amostras de solo da entrelinha da cultura foram coletadas quando as plantas atingiram o estádio $R_{2}$, para avaliação de taxa respiratória, biomassa microbiana, quociente metabólico, potencial de solubilização de fosfato inorgânico e potencial hidrogeniônico do solo. Quanto à taxa respiratória do solo, não se observaram alterações com a utilização dos diferentes manejos fitossanitários. Os herbicidas avaliados interferiram em características como o $\mathrm{CBM}$ e $\mathrm{qCO}_{2}$ - variáveis diretamente relacionadas à qualidade do solo. O glyphosate aplicado em dose única ou sequencial associado ou não com endossulfan + tebuconazole apresentou os menores valores de $\mathrm{qCO}_{2}\left(0,075-0,079 \mathrm{mg} \mathrm{mg}^{-1} \mathrm{~d}^{-1}\right)$ e os maiores de CBM $\left(239,64-312,82 \mathrm{mg} \mathrm{g}^{-1}\right)$, indicando menor grau de distúrbio do solo. Maiores atividades de solubilização de fosfato $\left(425\right.$ e $\left.472 \mathrm{mg} \mathrm{L}^{-1}\right)$ foram observadas nos tratamentos com aplicação única ou sequencial de glyphosate, respectivamente, sem combinação com endossulfan + tebuconazole. A aplicação dos agrotóxicos na parte aérea das plantas de soja interfere na atividade dos microrganismos associados à rizosfera.
\end{abstract}

Palavras-chave: biomassa microbiana, soja transgênica, quociente metabólico.

\begin{abstract}
The objective of this work was to evaluate the microbial activity and phosphate solubilization potential of a soil cultivated with soybean under different phytosanitary management strategies. The experiment was conducted in the field in a Cambic red-yellow Argisol. Ten treatments were arranged in a randomized block design with four replications. The effect of fungicide + herbicide application (endosulphan + tebuconazole) was evaluated in the plots, while weed control management was studied in the subplots (hoed or unhoed control; single-dose or sequential glyphosate application; single-dose fomesafen + fluazifop-p-butil application). Soil samples from the inter-row were collected when plants reached the $R_{2}$ stage and were used to measure soil respiratory rate, microbial biomass carbon (MBC), metabolic quotient $\left(\mathrm{qCO}_{2}\right)$, phosphate solubilization potential, and $\mathrm{pH}$. The phytosanitary management strategies evaluated did not affect soil respiratory rates. The herbicides tested influenced soil $\mathrm{MBC}$ and $\mathrm{qCO}_{2}$, variables directly related to soil quality. Glyphosate applied in a
\end{abstract}

1 Recebido para publicação em 26.3.2009 e na forma revisada em 13.11.2009.

2 Pesquisador do Programa Nacional de Pós-Doutorado - PNPD/CAPES na Universidade Federal do Tocantins - UFT, Rua Badejós, Chácaras 69 e 72, Zona Rural, Campus de Gurupi, 77404-970 Gurupi-TO, <reisagro@yahoo.com.br>; ${ }^{3}$ D.Sc., Professor Associado - DFT/UFV; ${ }^{4}$ Graduando do curso de Agronomia, Bolsista de Iniciação Científica - DFT/UFV; ${ }^{5}$ D. Sc., Professor do Depto. de Microbiologia - MBI/UFV; ${ }^{6}$ D.Sc., Professor do Depto. de Biologia Animal - DBA/UFV; ${ }^{7}$ Engํ-Agr ${ }^{0}$. , D.Sc., Pós-Doutorando em Fitotecnia - DFT/UFV. 
single dose or sequentially, either in combination with endosulphan + tebuconazole or not, led to lower $\mathrm{CCO}_{2}$ values $\left(0.075-0.079 \mathrm{mg} \mathrm{\mu g}^{-1} \mathrm{~d}^{-1}\right)$ and higher $\mathrm{MBC}(239.64-312.82 \mu \mathrm{g} \mathrm{g}$ ), indicating less soil disturbance. Higher phosphate solubilizing activity, 425 and $472 \mathrm{mg} \mathrm{L}^{-1}$, were observed for the treatments with single-dose or sequential application of glyphosate, respectively, in the absence of endosulfan + tebuconazole. Agrochemical application on soybean shoots affects the activity of soil microorganisms in the plant rhizosphere.

Keywords: microbial biomass, transgenic soybean, metabolic quotient.

\section{INTRODUÇÃO}

O Brasil é o maior consumidor de agrotóxicos do mundo, já superando os EUA; na safra de 2008 foram comercializados cerca de sete bilhões de dólares no País (Andef, 2009). Entre esses agrotóxicos, o maior volume comercializado se refere a herbicidas. A adoção do cultivo de soja transgênica resistente ao glyphosate tem levado ao consumo intensivo desse herbicida para controle de plantas daninhas, em vista da concomitante adoção do plantio direto em detrimento do convencional, das alterações na comunidade de plantas daninhas com o estabelecimento de espécies tolerantes ou resistentes e das estratégias de mercado (Bonny et al., 2007). Todavia, o aumento do consumo de herbicidas pode levar a maiores impactos ambientais negativos, principalmente aqueles relacionados ao solo, considerando-se que cerca de 60-70\% do herbicida aplicado em pós-emergência pode atingir direta ou indiretamente esse ambiente (Law et al., 2001). A aplicação de herbicidas pode alterar a atividade microbiana do solo, a depender do herbicida aplicado, do tipo de solo, da espécie da planta e da microbiota e suas interações (Santos et al., 2005; Reis et al., 2008).

A atividade microbiana, medida pela evolução de $\mathrm{CO}_{2}$, do solo tem sido utilizada como estimador da atividade fisiológica da microbiota do solo e das consequências das práticas agrícolas sobre ecossistemas (Tótola \& Chaer, 2002). A biomassa microbiana é responsável por funções essenciais ao solo, a exemplo da decomposição de matéria orgânica, da ciclagem de nutrientes minerais, da promoção de crescimento de plantas, do controle biológico e da degradação de compostos no solo. Ela tem sido proposta como parâmetro sensivel aos distúrbios provocados nesse ambiente, sobretudo em relação àqueles resultantes da aplicação de substâncias xenobióticas (Wardle, 1994; Sylvia et al., 2005). Para melhor interpretação da qualidade do solo, utiliza-se frequentemente o quociente metabólico $\left(\mathrm{qCO}_{2}\right)$, que representa a relação entre a evolução de $\mathrm{CO}_{2}$ e o carbono da biomassa microbiana do solo (Anderson \& Domsch, 1985). Esse quociente é considerado um indicador da qualidade do solo e parte do pressuposto de que, à medida que a biomassa microbiana se torna eficiente em utilizar os recursos, menor quantidade de carbono é perdida como $\mathrm{CO}_{2}$ pela respiração. O carbono é imobilizado nas células microbianas; assim, menor $\mathrm{qCO}_{2}$ representa biomassa microbiana em condição de equilíbrio, ou seja, ambiente com menor grau de distúrbio.

O glyphosate, em teoria, não altera a atividade microbiana do solo, devido à sua inativação no solo pela ligação do grupo fosfato presente na molécula aos sesquióxidos de ferro e alumínio (Lancaster et al., 2006; Pereira et al., 2008). A taxa respiratória nem sempre é sensivel aos distúrbios do solo, por ser atividade redundante nesse ambiente, sendo realizada por diferentes microrganismos. Já a biomassa microbiana pode sofrer parcialmente a inibição por alguns agrotóxicos aplicados. No entanto, microrganismos tolerantes sobressaem em detrimento dos sensiveis, não havendo alteração na biomassa microbiana total.

A análise minuciosa dos efeitos do glyphosate no solo requer estudos quantitativos e qualitativos da microbiota ali presente, a exemplo das avaliações de atividades específicas desempenhadas por determinados grupos microbianos ou funcionais. Tótola \& Chaer (2002) e Das et al. (2003) enfatizaram que as atividades dos microrganismos envolvidas nos ciclos biogeoquímicos são consideradas bons 
indicadores de qualidade do solo, visto que influenciam diretamente a disponibilidade dos nutrientes e auxiliam na elucidação das mudanças de funcionamento do ecossistema solo.

Entre os grupos funcionais, o dos microrganismos solubilizadores de fosfato inorgânico (MSFI) é bem adequado como indicador da qualidade do solo, principalmente em solos tropicais. Apesar de presente em grande quantidade no solo, o nutriente fósforo $(\mathrm{P})$ é encontrado em baixíssimas concentrações na solução do solo: 0,1 a $1,0 \mathrm{mg} \mathrm{L}^{-1}$ de $\mathrm{H}_{2} \mathrm{PO}_{4}$ (Novais et al., 2007). Grande parte do $\mathrm{P}$ indisponivel encontra-se precipitada com cálcio (P-Ca) em solos menos ácidos e ferro (P-Fe) e alumínio (P-Al) em solos mais ácidos. Para redisponibilização do $\mathrm{P}$ precipitado, as plantas e os MSFI acidificam naturalmente o solo rizosférico por meio da liberação de prótons e ácidos orgânicos (Rodríguez \& Fraga, 1999; Novais et al., 2007). Os MSFI são responsáveis pela liberação de ácidos orgânicos, como o glucônico, cítrico, glutâmico, oxálico, lático, fumárico, tartárico e succínico, os quais atuam como doadores de prótons e agentes quelantes dosíons $\mathrm{Ca}, \mathrm{Al}$ e $\mathrm{Fe}$, favorecendo a solubilização do fosfato inorgânico do solo (Rodríguez \& Fraga, 1999). Os MSFI constituem cerca de 5 a $10 \%$ da microbiota total dos solos e são encontrados na maioria destes. A diversidade e as populações dos MSFI são consideravelmente superiores em solos circunvizinhos às raízes das plantas, ou seja, nos solos rizosféricos (Nahas et al., 1994; Nautiyal, 1999). Também, os MSFI apresentam a capacidade de promover o crescimento de plantas pela exsudação de fitormônios, vitaminas e antibióticos. Além disso, a população e a atividade dos MSFI estão relacionadas com o manejo e tipo do solo, sendo considerados indicadores microbiológicos associados ao ciclo do $\mathrm{P}$ no solo (Kucey, 1983; Nahas et al., 1994; Carneiro et al., 2004). Pode ainda contribuir para a adoção de práticas agrícolas menos impactantes negativamente ao ambiente. No entanto, no Brasil há poucos estudos que evidenciam possiveis impactos da aplicação de herbicidas sobre os MSFI do solo (Massenssini et al., 2008; Reis et al., 2008).

Diante do exposto, objetivou-se com este trabalho avaliar a respiração e a biomassa microbiana, o quociente metabólico do solo rizosférico e o potencial de solubilização de fosfato em solos cultivados com soja tratada com herbicidas aplicados isoladamente ou em conjunto com inseticidas e fungicidas.

\section{MATERIAL E MÉTODOS}

O experimento foi conduzido em campo na estação experimental da Universidade Federal de Viçosa, Coimbra-MG (S 20 $0^{\circ} 5^{\prime} 20^{\prime \prime}$ e W 42。 52' 40"; altitude de $700 \mathrm{~m}$ ), entre os meses de dezembro e abril no biênio agrícola 2007/08, em Argissolo Vermelho-Amarelo câmbico, caracterizado química e fisicamente (Tabela 1).

Aos 15 dias antes da semeadura da soja, realizou-se a dessecação química da área com glyphosate + 2,4-D $\left(1.440+470 \mathrm{~g} \mathrm{ha}^{-1}\right)$ em mistura no tanque. A semeadura direta da soja BRS Favorita RR (Roundup Ready ${ }^{\circledR}$ ) foi realizada na primeira quinzena do mês de dezembro. As sementes foram tratadas com carbendazin + tiram $\left(0,30+0,70 \mathrm{~g} \mathrm{~kg}^{-1}\right.$ de sementes) e inoculadas com estirpes de Bradyrhizobium japonicum SEMIA 587 e SEMIA 5019 (4,2 x $10^{9}$ células viáveis $\mathrm{kg}^{-1}$ de sementes). Posteriormente ao

Tabela 1 - Principais características físicas e químicas do Argissolo Vermelho-Amarelo câmbico cultivado com soja Roundup Ready ${ }^{\circledR}$ no período compreendido entre dezembro/2007 e abril/2008. Coimbra-MG, 2007/08

\begin{tabular}{|c|c|c|c|c|c|c|c|c|c|c|}
\hline \multicolumn{11}{|c|}{ Análise granulométrica $\left(\mathrm{dag} \mathrm{kg}^{-1}\right)$} \\
\hline Argila & \multicolumn{2}{|c|}{ Silte } & \multicolumn{2}{|c|}{ Areia fina } & \multicolumn{3}{|c|}{ Areia grossa } & \multicolumn{3}{|c|}{ Classificação textural } \\
\hline 51 & \multicolumn{2}{|c|}{13} & \multicolumn{2}{|c|}{16} & & \multicolumn{2}{|l|}{20} & \multicolumn{3}{|c|}{ Argiloso } \\
\hline \multicolumn{11}{|c|}{ Análise química } \\
\hline $\mathrm{pH}$ & $\mathrm{P}$ & $\mathrm{K}^{+}$ & $\mathrm{H}+\mathrm{Al}$ & $\mathrm{Al}^{3+}$ & $\mathrm{Ca}^{2+}$ & $\mathrm{Mg}^{2+}$ & $\mathrm{CTC}_{\text {total }}$ & $\mathrm{V}$ & $\mathrm{m}$ & $\mathrm{MO}$ \\
\hline$\left(\mathrm{H}_{2} \mathrm{O}\right)$ & \multicolumn{2}{|c|}{$\left(\mathrm{mg} \mathrm{dm}^{-3}\right)$} & \multicolumn{5}{|c|}{$\left(\mathrm{cmol}_{\mathrm{c}} \mathrm{dm}^{-3}\right)$} & \multicolumn{2}{|c|}{$(\%)$} & $\left(\right.$ dag kg $\left.^{-1}\right)$ \\
\hline 5,40 & 10,4 & 138 & 5,78 & 0 & 2,40 & 0,80 & 9,33 & 38 & 0 & 1,70 \\
\hline
\end{tabular}


plantio, demarcaram-se 40 parcelas $(10 \times 10 \mathrm{~m})$. Utilizou-se o delineamento em blocos casualizados no esquema de parcelas subdivididas, com quatro repetições. Nas parcelas, avaliouse o efeito da aplicação ou não da mistura de inseticida + fungicida e, nas subparcelas, o efeito dos métodos de controle de plantas daninhas. As aplicações do inseticida endossulfan (525 $\mathrm{g} \mathrm{ha}^{-1}$ ) e do fungicida tebuconazole (150 $\mathrm{g} \mathrm{ha}^{-1}$ ), em mistura no tanque, foram realizadas aos 45 e 90 dias após emergência (DAE) das plântulas de soja. Os métodos de controle de plantas daninhas foram: 1testemunha não capinada; 2 - testemunha capinada; 3 - aplicação única de glyphosate ( $1.080 \mathrm{~g} \mathrm{ha}^{-1}$ ) aos $15 \mathrm{DAE} ; 4$ - aplicação sequencial de glyphosate (1.080 $\left.\mathrm{g} \mathrm{ha}^{-1}\right)$ aos 15 , 30 e 45 DAE; e 5 - aplicação de fomesafen + fluazifop-p-butil $\left(180+225 \mathrm{~g} \mathrm{ha}^{-1}\right)$ aos $15 \mathrm{DAE}$. Os dados diários de precipitação pluvial, umidade relativa e temperatura média foram coletados em estação meteorológica localizada próxima à área de plantio durante todo o período de condução do experimento (Figura 1).
Amostras de solo da entrelinha e do solo rizosférico da cultura foram coletadas quando as plantas atingiram o estádio $R_{2}$ para avaliação de taxa respiratória, biomassa microbiana, quociente metabólico, potencial de solubilização de fosfato inorgânico e potencial hidrogeniônico do solo.

Para avaliação da taxa respiratória, utilizou-se o método respirométrico para determinação do $\mathrm{C}-\mathrm{CO}_{2}$ evoluído do solo, segundo metodologia descrita por Vivian et al. (2006).

Para determinação do carbono da biomassa microbiana (CBM), pesaram-se duas subamostras de $20 \mathrm{~g}$ de solo em cada frasco usado na avaliação da taxa respiratória após período de incubação. Utilizou-se o método descrito por Vance et al. (1987), modificado por Islam \& Weil (1998), para estimar a biomassa microbiana, sendo as amostras tratadas com radiação de micro-ondas por $60+60$ segundos.

A partir dos valores obtidos para as taxas respiratórias e CBM do solo, calculou-se $\mathrm{qCO}_{2}$, dividindo-se a média diária do $\mathrm{C}-\mathrm{CO}_{2}$

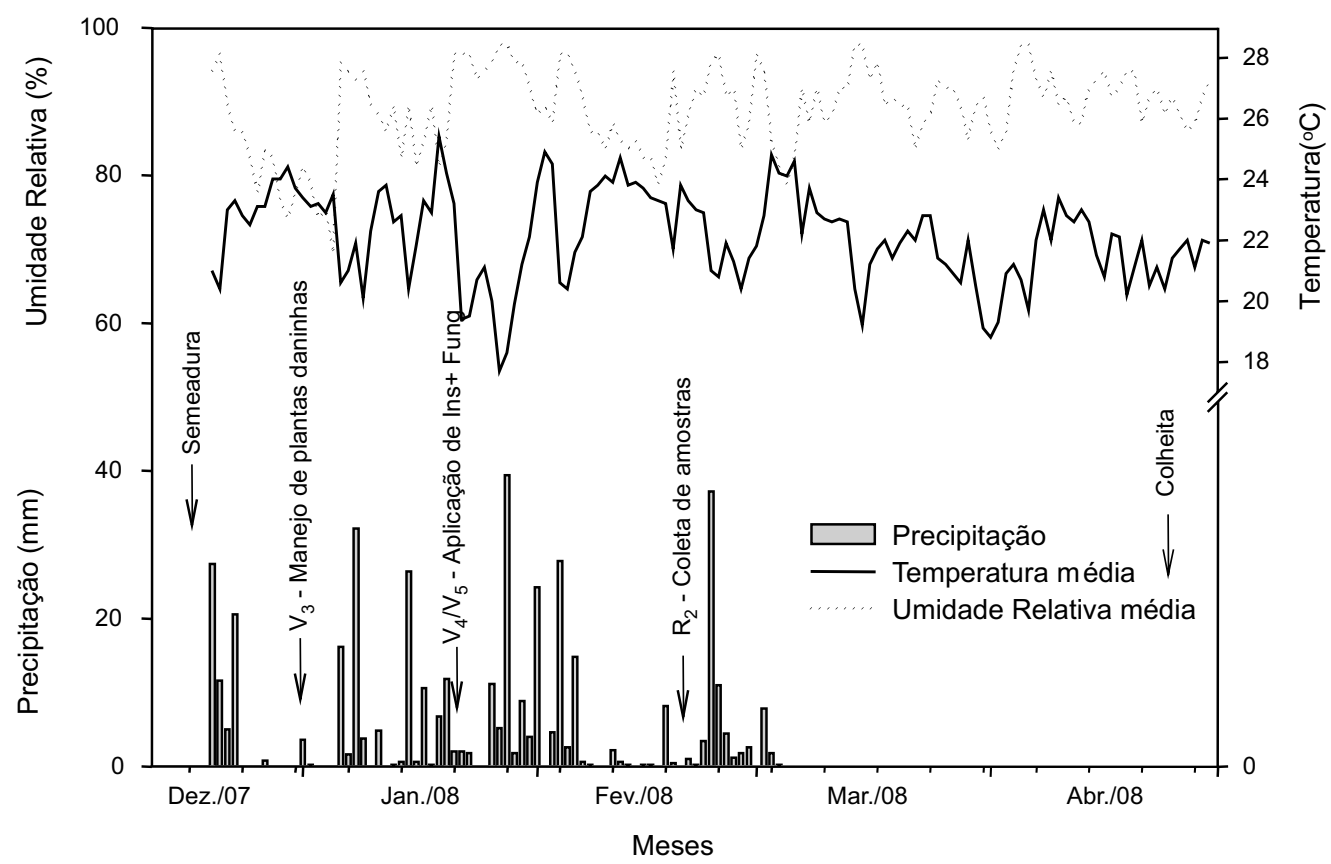

\footnotetext{
* As datas aproximadas de semeadura, manejo de plantas daninhas, aplicações de inseticidas e fungicidas e colheita estão assinaladas no período com o respectivo estádio fenológico da soja.
}

Figura 1 - Precipitação pluvial, umidade relativa e temperatura diária durante o período de 12 de dezembro de 2007 a 20 de abril de 2008. Coimbra-MG, 2007/08 
evoluído do solo pelo CBM determinado no solo (Anderson \& Domsch, 1985).

Para estimativa do potencial de solubilização de fosfato inorgânico em meio líquido, transferiu-se $1 \mathrm{~g}$ de solo rizoférico das amostras de cada repetição (oito plantas/ subparcela) para tubo de ensaio com meio líquido NBRI, pH 6,8-7,0, contendo $\left(\mathrm{g} \mathrm{L}^{-1}\right)$ : glicose, 10; $\mathrm{Ca}_{3}\left(\mathrm{PO}_{4}\right)_{2}, 5 ; \mathrm{MgCl}_{2} \cdot 6 \mathrm{H}_{2} \mathrm{O}, 0,5$; $\mathrm{MgSO}_{4} \cdot 7 \mathrm{H}_{2} \mathrm{O}, 0,25 ; \mathrm{KCl}, 0,2 ; \mathrm{e}\left(\mathrm{NH}_{4}\right)_{2} \mathrm{SO}_{4}, 0,1$ (Nautyal, 1999). Após incubação por 15 dias a $27^{\circ} \mathrm{C}$, a fase líquida foi submetida à centrifugação a $8.000 \mathrm{rpm}$ por $20 \mathrm{~min}$. No sobrenadante, determinou-se a quantidade de $\mathrm{P}$ inorgânico pelo método colorimétrico da vitamina $\mathrm{C}$ modificado, no comprimento de onda de $725 \mathrm{~nm}$ (Braga \& De Fellipo, 1974).

$\mathrm{O}$ pH do solo foi estimado a partir da solução solo:água $(1: 2,5)$ agitada por 30 minutos e colocada em repouso por mais 30 minutos (Embrapa, 1997).

Os dados foram submetidos à análise de variância $(P<0,05)$. Para comparação das médias dos tratamentos, utilizou-se o teste de Tukey $(\mathrm{P}<0,05)$.

\section{RESULTADOS E DISCUSSÃO}

Os tratamentos avaliados não alteraram a taxa respiratória do solo (Tabela 2). Pereira et al. (2008) não constataram diferenças nas taxas respiratórias do solo após aplicação de glyphosate sobre a microbiota do solo cultivado com soja transgênica. No entanto, esses autores constataram que esse produto aplicado em associação com endossulfan propiciou maior evolução de $\mathrm{CO}_{2}$ em relação à aplicação de glyphosate isoladamente. Por outro lado, em alguns trabalhos, o glyphosate isolado induziu maiores taxas respiratórias iniciais em relação ao controle sem aplicação de herbicida, indicando a possível metabolização do glyphosate pela biota do solo (Costa et al., 1997; Moreno et al., 2007).

Para o carbono da biomassa microbiana (CBM), nos tratamentos sem aplicação de endossulfan + tebuconazole, não se observou diferença entre os métodos de controle de plantas daninhas (Tabela 3). No entanto, para os tratamentos com aplicação de endossulfan + tebuconazole, as parcelas tratadas com fomesafen + fluazifop-p-butil e a testemunha sem capina apresentaram os menores valores de CBM em relação à testemunha capinada e à aplicação única ou sequencial de glyphosate (Tabela 3). A mistura fomesafen + fluazifop-pbutil parece ser mais danosa à população de microrganismos do solo, pois a redução do $\mathrm{CBM}$ foi mais pronunciada $(65,05 \%)$ em relação à testemunha capinada, na situação de aplicação de fomesafen + fluazifop-p-butil e endossulfan + tebuconazole. Isso pode ser devido ao possivel efeito sinergístico entre ambas as misturas, potencializando desse modo o efeito negativo desses compostos sobre os microrganismos do solo. Santos et al. (2005) avaliaram o efeito dos herbicidas fluazifop-pbutil e fomesafen, isolados e em mistura, nos atributos biológicos de qualidade do solo

Tabela 2 - Taxa respiratória de solo cultivado com soja BRS Favorita RR submetida a diferentes métodos de controle de plantas daninhas, com ou sem aplicação de endossulfan + tebuconazole. Coimbra-MG, 2007/08

\begin{tabular}{|c|c|c|}
\hline \multirow{2}{*}{ Método de controle de plantas daninhas } & \multicolumn{2}{|c|}{ Taxa respiratória $\left(\mathrm{mg} \mathrm{g}^{-1} \mathrm{~d}^{-1}\right)^{*}$} \\
\hline & sem $\mathrm{E}+\mathrm{T}^{* *}$ & com $\mathrm{E}+\mathrm{T}$ \\
\hline Testemunha não capinada & $21,75 \mathrm{aA}^{1 / /}$ & $18,00 \mathrm{aA}$ \\
\hline Testemunha capinada & $16,77 \mathrm{aA}$ & $16,77 \mathrm{aA}$ \\
\hline Aplicação única de glyphosate & $17,51 \mathrm{aA}$ & $13,60 \mathrm{aA}$ \\
\hline Aplicação sequencial de glyphosate & $19,25 \mathrm{aA}$ & $16,54 \mathrm{aA}$ \\
\hline Aplicação única de fomesafen + fluazifop-p-butil & $15,88 \mathrm{aA}$ & $11,32 \mathrm{aA}$ \\
\hline CV parcela $(\%)$ & \multicolumn{2}{|c|}{19,83} \\
\hline CV subparcela $(\%)$ & \multicolumn{2}{|c|}{16,59} \\
\hline
\end{tabular}

* Solo coletado quando as plantas de soja atingiram o estádio $\mathrm{R}_{2}$, ou seja, $50 \%$ do florescimento pleno. $* * \mathrm{E}+\mathrm{T}=$ endossulfan + tebuconazole. ${ }^{1 /}$ Médias seguidas pela mesma letra, minúscula na coluna e maiúscula na linha, para cada variável, não diferem entre si pelo teste de Tukey $(\mathrm{P}>0,05)$. 
Tabela 3 - Carbono da biomassa microbiana (CBM) de solo cultivado com soja BRS Favorita RR submetida a diferentes métodos de controle de plantas daninhas, com ou sem aplicação de endossulfan + tebuconazole. Coimbra-MG, 2007/08

\begin{tabular}{|l|c|c|}
\hline \multirow{2}{*}{ Método de controle de plantas daninhas } & \multicolumn{2}{c|}{ Biomassa microbiana $\left(\mathrm{g} \mathrm{g}^{-1} \mathrm{CBM}^{*}\right.$} \\
\cline { 2 - 3 } & $\mathrm{sem} \mathrm{E}+\mathrm{T}^{* *}$ & $147,27 \mathrm{bA}$ \\
\hline Testemunha não capinada & $136,12 \mathrm{aA}^{\underline{1}}$ & $237,74 \mathrm{abA}$ \\
\hline Testemunha capinada & $233,14 \mathrm{aA}$ & $239,64 \mathrm{abA}$ \\
\hline Aplicação única de glyphosate & $229,30 \mathrm{aA}$ & $312,82 \mathrm{aA}$ \\
\hline Aplicação sequencial de glyphosate & $250,16 \mathrm{aA}$ & $83,05 \mathrm{bA}$ \\
\hline Aplicação única de fomesafen + fluazifop-p-butil & $148,81 \mathrm{aA}$ & - \\
\hline C.V. parcela (\%) & - & 43,81 \\
\hline C.V. subparcela (\%) & 31,05 & - \\
\hline
\end{tabular}

* Solo coletado quando as plantas de soja atingiram o estádio $\mathrm{R}_{2}$, ou seja, $50 \%$ do florescimento pleno. $* * \mathrm{E}+\mathrm{T}=$ endossulfan + tebuconazole. ${ }^{1 /}$ Médias seguidas pela mesma letra, minúscula na coluna e maiúscula na linha, para cada variável, não diferem entre si pelo teste de Tukey $(\mathrm{P}>0,05)$

cultivado com feijão (Phaseolus vulgaris) em sistema de cultivo convencional e plantio direto. Em ambos os cultivos constataram-se maiores reduções na biomassa microbiana do solo tratado com a mistura de fluazifop-p-butil e fomesafen. Também, Pereira et al. (2008) demonstraram que o endossulfan causou redução de $48,64 \%$ no CBM de solo cultivado com soja, em relação ao controle sem aplicação de agrotóxicos. No entanto, não se encontraram trabalhos na literatura avaliando os efeitos das duas misturas aplicadas simultaneamente. Ao avaliar o efeito da aplicação de endossulfan + tebuconazole, não se observaram diferenças entre os manejos de plantas daninhas (Tabela 3).

Com relação aos valores do quociente metabólico $\left(\mathrm{qCO}_{2}\right)$, estimados no estádio $\mathrm{R}_{2}$ da soja, observou-se que, na ausência de endossulfan + tebuconazole, os solos tratados com glyphosate em aplicação única ou sequencial, fomesafen + fluazifop-p-butil e a testemunha capinada não apresentaram diferenças, sendo valores inferiores aos da testemunha não capinada (Tabela 4). Esse fato pode ser devido à incorporação de matéria orgânica (plantas daninhas) no solo quando a capina é realizada, pois o material orgânico depositado no solo servirá como fonte de carbono e energia para os microrganismos, tendendo a uma condição de equilíbrio.

No entanto, nos tratamentos onde os herbicidas foram aplicados juntamente com endossulfan + tebuconazole, as parcelas tratadas com glyphosate em dose única e sequencial apresentaram os menores valores de $\mathrm{qCO}_{2}$, diferindo dos demais tratamentos, com destaque para a área tratada com fomesafen + fluazifop-p-butil e para a testemunha sem capina. Ao comparar os tratamentos em que os métodos de controle de plantas daninhas foram aplicados em associação ou não com endossulfan + tebuconazole, não se verificaram diferenças (Tabela 4).

Para o P solubilizado, constataram-se diferenças entre os métodos de controle de plantas daninhas nas áreas onde eles foram executados sem a aplicação de endossulfan + tebuconazole (Tabela 5). O glyphosate em aplicação única e sequencial promoveu maior solubilização de fosfato, embora Massenssini et al. (2008) tenham relatado que o glyphosate nas formulações comerciais - Roundup NA e Transorb, Scout, Zapp QI - foi prejudicial à atividade de bactérias solubilizadoras de fosfato isoladas da rizosfera de eucalipto. Contudo, tal estudo foi conduzido in vitro, isolando dessa forma a interação planta-microrganismo-solo. Essa maior promoção de solubilização de fosfato pode estar associada à maior exsudação radicular das plantas de soja tratadas com glyphosate, havendo maior incremento de $\mathrm{C} \mathrm{e}$ energia na rizosfera, com o consequente favorecimento da atividade microbiana. Segundo Kremer et al. (2005), a aplicação de glyphosate em plantas de soja promove aumento na quantidade e alterações na composição do material exsudado, o que pode aumentar a biomassa microbiana associada a essas plantas. Maior incremento no CBM foi observado com a aplicação do glyphosate (Tabela 3); portanto, há maior evolução de $\mathrm{CO}_{2}$, que, ao 
ser liberado na solução do solo, reage com $\mathrm{H}_{2} \mathrm{O}$, formando o ácido carbônico $\left(\mathrm{H}_{2} \mathrm{CO}_{3}\right)$. Dessa forma, ocorre a acidificação da solução do solo (Tabela 5) e, consequentemente, promoção da solubilização de fosfatos. Na presença da mistura endossulfan + tebuconazole, o glyphosate em aplicação única e sequencial e a testemunha capinada propiciaram os maiores valores de solubilização de fosfato, diferenciando-se da testemunha sem capina (Tabela 5).

Os tratamentos com aplicação de fomesafen + fluazifop-p-butil e capina mecânica mostraram os menores valores de $\mathrm{P}$ solubilizado. O menor valor de solubilização de fosfato foi observado na parcela não capinada (Tabela 5). A mistura fomesafen + fluazifop-pbutil apresentou os menores valores de $\mathrm{pH}$ independentemente da presença ou não de endossulfan + tebuconazole (Tabela 5), não sendo verificada maior solubilização de P. Esse fato pode ser atribuído à redução drástica da biomassa microbiana, sendo observado decréscimo de 65,05 e 37,18\% no CBM nas parcelas tratadas com essa mistura associada ou não com endossulfan + tebuconazole, respectivamente (Tabela 3). Ao comparar os métodos de controle de plantas daninhas com aplicação ou não de endossulfan + tebuconazole, observouse que houve maior solubilização de fosfato nas parcelas em que o glyphosate foi aplicado em dose única e sequencial, sem aplicação de endossulfan + tebuconazole (Tabela 5).

Em trabalho realizado por Reis et al. (2008) constatou-se que a atividade dos microrganismos solubilizadores de fosfato não foi influenciada negativamente pelo 2,4-D, ametryn, trifloxysulfuron-sodium e ametryn + trifloxysulfuron-sodium, sendo ainda

Tabela 4 - Quociente metabólico $\left(\mathrm{qCO}_{2}\right)$ de solo cultivado com soja BRS Favorita RR submetida a diferentes métodos de controle de plantas daninhas, com ou sem aplicação de endossulfan + tebuconazole. Coimbra-MG, 2007/08

\begin{tabular}{|l|c|c|}
\hline \multirow{2}{*}{ Método de controle de plantas daninhas } & \multicolumn{2}{|c|}{$\mathrm{q} \mathrm{CO}_{2}\left(\mathrm{mg} \mathrm{CO}_{2} \mathrm{~g} \mathrm{CBM}^{-1} \mathrm{~d}^{-1}\right)^{*}$} \\
\cline { 2 - 3 } & $\mathrm{sem} \mathrm{E+T} * *$ & $0,130 \mathrm{bA}$ \\
\hline Testemunha não capinada & $0,145 \mathrm{bA}^{\frac{1}{}}$ & $0,071 \mathrm{abA}$ \\
\hline Testemunha capinada & $0,080 \mathrm{aA}$ & $0,079 \mathrm{aA}$ \\
\hline Aplicação única de glyphosate & $0,075 \mathrm{aA}$ & $0,075 \mathrm{aA}$ \\
\hline Aplicação sequencial de glyphosate & $0,078 \mathrm{aA}$ & $0,136 \mathrm{bA}$ \\
\hline Aplicação única de fomesafen + fluazifop-p-butil & $0,113 \mathrm{abA}$ & \\
\hline CV parcela (\%) & & 29,09 \\
\hline CV subparcela (\%) & 11,99 & \\
\hline
\end{tabular}

* Solo coletado quando as plantas de soja atingiram o estádio $\mathrm{R}_{2}$, ou seja, $50 \%$ do florescimento pleno. $* * \mathrm{E}+\mathrm{T}=$ endossulfan + tebuconazole. ${ }^{1 /}$ Médias seguidas pela mesma letra, minúscula na coluna e maiúscula na linha, para cada variável, não diferem entre si pelo teste de Tukey $(\mathrm{P}>0,05)$.

Tabela 5 - Fósforo $(\mathrm{P})$ solubilizado e potencial hidrogenionico $(\mathrm{pH})$ de solo cultivado com soja BRS Favorita RR submetida a diferentes métodos de controle de plantas daninhas, com ou sem aplicação de endossulfan + tebuconazole. Coimbra-MG, 2007/08

\begin{tabular}{|c|c|c|c|c|}
\hline \multirow{2}{*}{ Método de controle de plantas daninhas } & \multicolumn{2}{|c|}{ P solubilizado $\left(\mathrm{mg} \mathrm{L}^{-1}\right)^{*}$} & \multicolumn{2}{|c|}{$\mathrm{pH}^{*}$} \\
\hline & $\operatorname{sem} \mathrm{E}+\mathrm{T} * *$ & com E+T & sem E+T & Com E+T \\
\hline Testemunha não capinada & $74,50 \mathrm{cA}^{\underline{1} /}$ & $111,50 \mathrm{bA}$ & $6,06 \mathrm{aA}$ & $5,58 \mathrm{abB}$ \\
\hline Testemunha capinada & $126,00 \mathrm{cB}$ & $340,85 \mathrm{aA}$ & $5,92 \mathrm{abA}$ & $5,85 \mathrm{aA}$ \\
\hline Aplicação única de glyphosate & $425,00 \mathrm{aA}$ & $318,16 \mathrm{aB}$ & $5,83 \mathrm{abA}$ & $5,70 \mathrm{abA}$ \\
\hline Aplicação sequencial de glyphosate & $472,00 \mathrm{aA}$ & $373,50 \mathrm{aB}$ & $5,88 \mathrm{abA}$ & $5,47 \mathrm{bB}$ \\
\hline Aplicação única de fomesafen + fluazifop-p-butil & $193,00 \mathrm{bA}$ & $255,00 \mathrm{aB}$ & $5,67 \mathrm{bA}$ & $5,33 \mathrm{bB}$ \\
\hline CV parcela $(\%)$ & \multicolumn{2}{|c|}{18,27} & \multicolumn{2}{|c|}{2,61} \\
\hline CV subparcela $(\%)$ & \multicolumn{2}{|c|}{16,01} & \multicolumn{2}{|c|}{1,94} \\
\hline
\end{tabular}

* Solo coletado quando as plantas de soja atingiram o estádio $\mathrm{R}_{2}$, ou seja, $50 \%$ do florescimento pleno. ${ }^{* *} \mathrm{E}+\mathrm{T}=$ endossulfan + tebuconazole. ${ }^{1 /}$ Médias seguidas pela mesma letra, minúscula na coluna e maiúscula na linha, para cada variável, não diferem entre si pelo teste de Tukey $(\mathrm{P}>0,05)$. 
estimulada na presença de trifloxysulfuronsodium e 2,4-D. Comportamento semelhante foi observado para os herbicidas oxadiazon e oxyfluorfen, butachlor e basalin em trabalhos realizados respectivamente por Debnath et al. (2002) e Das et al. (2003).

$\mathrm{O}$ pH do solo reduziu com a aplicação de fomesafen + fluazifop-p-butil nas parcelas tratadas somente com herbicidas (Tabela 5). No entando, quando na presença de endossulfan + tebuconazole não foi observada diferença entre os métodos de controle de plantas daninhas em relação à testemunha não capinada (Tabela 5). Taiwo \& Oso (1997) verificaram que em solos tratados com atrazine houve redução de quase uma unidade de $\mathrm{pH}$ no solo e, consequentemente, acréscimo de quase $5 \mathrm{mg} \mathrm{kg}^{-1}$ de Pi na solução do solo.

Com base nos resultados, pode-se concluir que os métodos de controle de plantas daninhas em soja interferiram nas características CBM e $\mathrm{qCO}_{2}$, variáveis diretamente relacionadas à qualidade do solo, associados ou não à aplicação de endossulfan + tebuconazole. O glyphosate em aplicação única ou sequencial associado à mistura endossulfan + tebuconazole promoveu os menores valores de $\mathrm{qCO}_{2}$, indicando menor grau de distúrbio do solo. A atividade dos microrganismos solubilizadores de fosfato foi influenciada positivamente pelo glyphosate em aplicação única ou sequencial em combinação com endossulfan + tebuconazole.

\section{AGRADECIMENTOS}

Ao Conselho Nacional de Desenvolvimento Científico e Tecnológico (CNPq), pela concessão de bolsas e pelo apoio financeiro para a realização deste trabalho.

\section{LITERATURA CITADA}

AGENCIA NACIONAL DE DEFESA VEGETAL - ANDEF. Brasil supera EUA no consumo de agrotóxicos. Disponível em: $<$ http://www.andef.com.br/informativo/ andef201200910512. htm>. Acesso em: 22 de jan. de 2009

ANDERSON, J. P.; DOMSCH, K. H. The metabolic quotient for $\mathrm{CO}_{2}\left(\mathrm{qCO}_{2}\right)$ as a specific activity parameter to asses the effects of environmental conditions, such as $\mathrm{pH}$, on the microbial biomass of forest soils. Soil Biol. Biochem., v. 25, n. 3, p. 393-395, 1993.

Planta Daninha, Viçosa-MG, v. 27, n. 4, p. 729-737, 2009
BONNY, S. Genetically modified glyphosate-tolerant soybean in the USA: adoption factors, impacts and prospects. A review. Agron. Sustain. Dev., v. 28, n. 1, p. 1-12, 2007.

BRAGA, J. M.; DEFELIPO, B. V. Determinação espectrofotométrica de fósforo em extratos de solos e plantas R. Ceres, v. 21, n. 113, p. 73-85, 1974.

CARNEIRO, R. G. et al. Indicadores biológicos associados ao ciclo do fósforo em solos de cerrado sob plantio direto e plantio convencional. Pesq. Agropec. Bras., v. 39, n. 7 , p. 661-669, 2004.

COSTA, M. A.; MONTEIRO, R. T. R.; TORNISIELO, V. L. Influência da adição de palha de cana-de-açúcar na degradação de ${ }^{14} \mathrm{C}$-ametrina em solo areia quartzosa. Sci. Agric., v. 54, n. 3, p. 117-122, 1997.

DAS, A. C.; DEBNATH, A.; MUKHERJEE, D. Effect of the herbicides oxadiazon and oxyfluorfen on phosphates solubilizing microorganisms and their persistence in rice fields. Chemosphere, v. 53, p. 217-221, 2003.

DEBNATH, A.; DAS, A. C.; MUKHERJEE, D. Persistence and effect of butachlor and basalin on the activities of phosphate solubilizing microorganisms in wetland rice soil. B. Environ. Contam. Toxicol., v. 68, n. 5, p. 766-770, 2002.

EMBRAPA. CNPS. Manual de métodos de análises de solo. 2.ed. Rio de Janeiro, 1997, 212 p. (EMBRAPA-CNPS Documentos, 1).

ISLAM, K. R.; WEIL, R. R. Microwave irradiation of soil four routine measurement of microbial biomass carbon. Biol. Fert. Soils, v. 27, n. 4, p. 408-416, 1998.

KREMER, R. J.; MONTEIRO, R. T. R.; TORNISIELO, V. L. Glyphosate affects soybean root exudation and rhizosphere microorganisms. Inter. J. Environ. Anal. Chem., v. 85, n. 15, p. 1165-1174, 2005

KUCEY, R. M. N. Phosphate-solubilizing bacteria and fungi in various cultivated and virgin Alberta soils. Can. J. Soil. Sci., v. 63, n. 4, p. 671-678, 1983.

LANCASTER, S. R. et al. Soil microbial activity is affected by roundup weathermax and pesticides Applied to cotton (Gossypium hirsutum). J. Agric. Food Chem., v. 54, n. 19, p. $7221-7226,2006$.

LAW, S. E. Agricultural electrostatic spray applictation: a review of signigicant research and development during de $20^{\text {th }}$ century. Athens: University of Georgia, 2001. p. 25-42.

MASSENSSINI, A. M. et al. Atividade de isolados bacterianos solubilizadores de fosfato na presença de formulações comerciais de glyphosate. Planta Daninha, v. 26, n. 4 , p. $815-823,2008$ 
MORENO, J. L. et al. Effects of atrazine on microbial activity in semiarid soil. Appl. Soil Ecol., v. 35, n. 1, p. 120-127, 2007.

NAHAS, E.; CENTURION, J. F.; ASSIS, L. C. Microrganismos solubilizadores de fosfato e produtores de fosfatases de vários solos. R. Bras. Ci. Solo, v. 18, n. 1, p. 43-48, 1994.

NAUTIYAL, C. S. An efficient microbiological growth medium for screening phosphate solubilizing microorganisms. FEMS Microbiol. Letters, v. 170, n. 1, p. 265-270, 1999.

NOVAIS, R. F. et al. Fósforo em solo e planta em condições tropicais. In: NOVAIS, R. F et al. (Eds). Fertilidade do solo. Viçosa, MG: Sociedade Brasileira de Ciência do Solo, 2007. 1017 p.

PEREIRA, J. L. et al. Effects of glyphosate and endossulfan on soil microorganisms in soybean crop. Planta Daninha, v. 26, n. 4, p. $825-830,2008$

REIS, M. R. et al. Ação de herbicidas sobre microrganismos solubilizadores de fosfato inorgânico em solo rizosférico de cana-de-açúcar. Planta Daninha, v. 26, n. 2, p. 333-341, 2008.

RODRÍGUEZ, H.; FRAGA, R. Phosphate solubilizing bacteria and their role in plant growth promotion.

Biotechnol. Adv., v. 17, n. 4-5, p. 319-339, 1999.
SANTOS, J. B. et al. Atividade microbiana do solo após aplicação de herbicidas em sistemas de plantio direto e convencional. Planta Daninha, v. 23, n. 4, p. 683-691, 2005.

SYLVIA, D. M. et al. Principles and applications of soil microbiology. 2.ed. New Jersey, 2005. 645 p.

TAIWO, L. B.; OSO, B. A. The influence of some pesticides on soil microbial flora in relation to changes in nutrient level, rock phosphate solubilization and $\mathrm{P}$ release under laboratory conditions. Agric. Ecosys. Environ., v. 65, n. 1, p. 59-68, 1997.

TÓTOLA, M. R.; CHAER, G. M. Microrganismos e processos microbiológicos como indicadores da qualidade dos solos. In: ALVAREZ V., V. H. et al. (Eds.). Tópicos em ciência do solo. Viçosa, MG: Sociedade Brasileira de Ciência do Solo, 2002. v. 2. p. 195-276.

VANCE, E. D.; BROOKES, P. C.; JENKINSON, D. S. An extraction method for measuring soil microbial biomass $\mathrm{C}$. Soil. Biol. Biochem., v. 19, n. 6, p. 703-707, 1987.

VIVIAN, R. et al. Persistência de sulfentrazone em Latossolo Vermelho-Amarelo cultivado com cana-de-açúcar. Planta Daninha, v. 24, n. 4, p. 741-750, 2006.

WARDLE, D. A. Impact of disturbances on detritus foodwebs in agro-ecossystems of contrasting tillage and weed management practices. Adv. Ecol. Res., v. 26, p. 10-17, 1994. 